\title{
CONTROLE DE QUALIDADE NA MANIPULAÇÃO MAGISTRAL DA CAMELLIA SINENSIS (CHÁ VERDE)
}

\author{
Mariana dos Santos Ferreira ${ }^{1}$ \\ Alex Sandro Rodrigues Baiense ${ }^{2}$
}

RESUMO: O uso das plantas medicinais é praticado na humanidade desde a antiguidade, e continua a ser aplicado nos dias de hoje, através dos ensinamentos transmitidos de geração em geração, para o tratamento e para a cura de doenças. Ele surgiu com o descobrimento de suas propriedades curativas encontradas em determinadas plantas. Com essa descoberta dá-se a origem aos fitoterápicos, os quais são medicamentos produzidos através das plantas, ou de suas partes, com finalidade de tratar de patologias. $\mathrm{O}$ uso destes medicamentos se torna cada vez maior, devido ao baixo custo, a sua acessibilidade e por se tratarem produtos encontrados na natureza. $\mathrm{Na}$ atualidade, o chá verde, é uma das bebidas mais consumidas no mundo, sendo considerado um alimento funcional, que consumido na alimentação cotidiana pode trazer benefícios fisiológicos à saúde, graças aos seus componentes ativos, como os antioxidantes, flavonoides, catequinas, que atuam na prevenção de doenças. Entretanto, o controle de qualidade na preparação do chá deve obedecer às regras e normas para que o seu consumo traga benefícios ao ser ingerido.

Palavras-chave: Camellia Sinensis. Controle de Qualidade. Eficiência.

ABSTRACT: The use of medicinal plants has been practiced in mankind since antiquity, and continues to be used nowadays through the teachings transmitted from generation to generation for the treatment and cure of diseases, which arose with the discovery of their healing properties found in certain plants. With this discovery, herbal medicines are given rise, which are medicines produced through plants, or their parts, in order to treat pathologies. The use of these drugs becomes increasing, due to the low cost, their accessibility and because they are products found in nature. Nowadays, green tea is one of the most consumed beverages in the world, being considered a functional food, which consumed in everyday food can bring physiological benefits to health, thanks to its active components, such as antioxidants, flavonoids, catechins, which act in the prevention of diseases. However, quality control in the preparation of tea for consumption must comply with the rules and norms so that its consumption brings benefits when it is consumption Ed.

Keywords: Camellia Sinensis. Quality Control. Efficiency.

\footnotetext{
I Aluna do curso Bacharel em Farmácia da Universidade Iguaçu. E-mail: marisantos.ferreira.mf@gmail.com

${ }^{2}$ Orientador. Professor, farmacêutico industrial CRFRJ 7275E-mail: alexbaiense@gmail.com.
} 


\section{INTRODUÇÃO}

$\mathrm{Na}$ antiguidade, de acordo com registros históricos, os homens já conheciam as diferentes propriedades clínicas das plantas, se tornando o agente das alterações da evolução vegetal caseira. O meio botânico sempre esteve relacionado a sobrevivência do homem, desde o início da civilização humana. Utilizando este meio como forma de alimentação e farmacêutico. Também se faz necessário que se compreenda a cultura, visto que os rituais e os mitos em geral, influenciam na maneira de como o homem lida com seu próprio corpo e com a sua.

Desde a Antiguidade, as plantas têm sido utilizadas como medicamentos, na prevenção, no tratamento e na cura de distúrbios, disfunções ou doenças em homens e animais. O chá verde é consumido principalmente nos países Asiáticos, onde seu significado vai além de uma simples bebida, é sinônimo de prosperidade, harmonia, beleza e seu consumo torna-se um ritual de grande importância social e cultural (CLARKE et al., 2007).

O chá de um modo geral, uma das bebidas mais consumidas no mundo, é uma das fontes mais ricas em flavonoides, substâncias antioxidantes que atuam em diferentes níveis de proteção do organismo e que ajudam a neutralizar os radicais livres, impedindo sua formação e são responsáveis pelo envelhecimento celular precoce (MATSUBARA; RODRIGUEZ, 2006).

Todos os procedimentos exigidos pela legislação para o controle de qualidade da matéria prima vegetal devem ter como fundamento na, Farmacopeia Brasileira, outras farmacopeias reconhecidas pela Agência Nacional de Vigilância Sanitária (ANVISA) ou mediante os guias referentes ao controle de qualidade de espécies vegetais publicados pela Organização Mundial da Saúde.

Embora exista uma legislação específica que estabelece parâmetros que visam à qualidade, a comercialização de plantas medicinais nem sempre é acompanhada com rigor. Enfatiza-se a importância da identificação, manipulação e armazenamento correto do material botânico, além de especificações adequadas da qualidade microbiológica e estudos de segurança, eficácia e qualidade. 
Diante do exposto, o objetivo deste trabalho foi investigar os efeitos da utilização do chá verde para a saúde humana, bem como analisar os processos incorretos de manipulação e o armazenamento de maneira errada do material vegetal destinado ao preparo dos chás que podem possibilitar o aumento da umidade, que, associado à presença de fungos e bactérias, pode representar riscos pela produção de substâncias tóxicas, as quais podem levar à destruição e/ou alteração dos princípios ativos; assim, tornando-se impróprio para o consumo e acarretando prejuízos ao serem consumidos, desde a ausência dos efeitos benéficos esperados até possíveis efeitos colaterais. (AMARAL et al., 2003).

\section{OBJETIVOS}

\section{I Objetivo geral}

Investigar os efeitos da utilização do chá verde para a saúde humana, assim como levantar os possíveis benefícios e malefícios de seu uso

\subsection{Objetivos específicos}

- Discorrer acerca dos benefícios à saúde associados ao consumo do chá verde;

- Analisar o controle de qualidade referentes ao cultivo, coleta, armazenamento e processamento;

- Compreender sua composição química e biodisponibilidade

\section{METOdOlOGiA}

Para o presente estudo foi realizada uma pesquisa bibliográfica, baseadas na coleta de informações em livros, artigos e dissertações, no intuito de formar um referencial teórico consistente acerca do tema.

O procedimento bibliográfico permitirá que se tome conhecimento de material relevante, tomando-se por base o que já foi publicado em relação ao tema, de modo que se possa delinear uma nova abordagem sobre esses, chegando a conclusões que possam servir de embasamento para a pesquisa. Qualquer informação publicada (impressa ou eletrônica) 
será passível de se tornar uma fonte de consulta. O procedimento documental, conforme Gil (2007), tem o objetivo de descrever e comparar dados, características da realidade presente e do passado.

\section{JUSTIFICATIVA}

O presente estudo justifica-se devido ao fato de as plantas medicinais serem alvo de investigação e manipulação científica, entretanto, esta não é a realidade das pessoas quando fazem seu uso, visto que, na grande maioria das vezes sua utilização baseia- -se no pensamento comum e na herança cultural, representando assim, uma alternativa de tratamento de menor custo e equivalente eficácia, na perspectiva dos usuários.

Entretanto, não existe a preocupação quanto a qualidade destes produtos colocados à venda, visto que os mesmos além de possuírem um menor custo financeiro, não necessitam de prescrição médica.

\section{REVISÃO DA LITERATURA}

\section{I Camellia sinensis (chá verde)}

Segundo Bianco (200o), Camellia Sinensis é uma planta de origem asiática pertencente à família Theaceae do gênero Camellia e espécie sinensis. Conhecida popularmente como chá verde, chá da índia, chá preto ou "green tea", o seu cultivo, que ocorre em mais de trinta países do mundo, origina-se preferencialmente por meio de estacas possuindo uma folha desenvolvida da planta com um tamanho de três a quatro centímetros. Ela é do tipo arbustivo de pequeno porte, folhas simples, alternas e inteiras, suas margens são serreadas e sua textura coriácea (DUARTE, MENARIM, 2006).

Figura I: Folhas da Camellia Sinensis

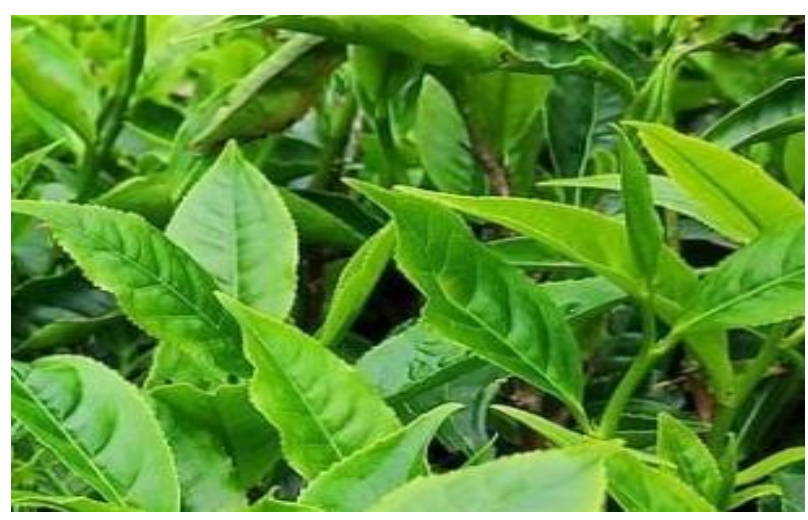


Bianco (2000) relata que as suas flores são pequenas, brancas, geralmente possui de quatro a cinco pétalas, e aparecem em grupos de até quatro. Seu fruto é uma cápsula com até três centímetros de diâmetro

Figura 2: Flores da Camellia Sinensis

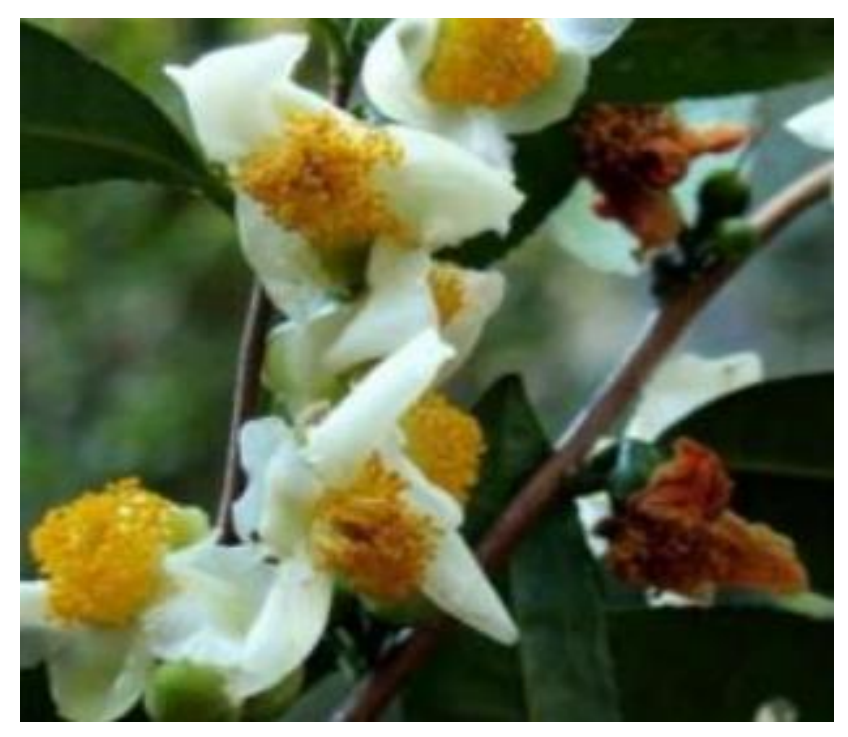

Esta planta dá origem a três tipos de chás que são, a partir da sua preparação após a colheita, considerados diferentes, originando da mesma planta. Portanto, quando as folhas são submetidas à fermentação rápida ou prolongadas se tem o chá preto e o Oolong, respectivamente. Já o famoso chá verde, é obtido através da consolidação das folhas recémcoletadas, onde as mesmas passam por um aquecimento para que ocorra a inativação das enzimas catalíticas prevenindo a oxidação dos bioativos do chá (RADOMINSKI, 2007 in SÁ, TURELLA, BETTEGA, 2007).

A composição fitoquímica das folhas da Camellia Sinensis depende de vários fatores como clima, práticas de cultivo, estação do ano, variedade e idade da planta. Duarte e Menarim (2006) descobriram que ela possui em sua composição química diferentes grupos de compostos constituídos principalmente de polifenóis.

A busca por um aprofundamento relacionado ao conhecimento dos efeitos do chá verde, fez com que sua complexa composição química tenha sido estudada através de métodos analíticos e quimiométricos (SENGER, 2010). Ele tem seus benefícios à saúde 
atribuídos a altas concentrações de antioxidantes e de compostos fenólicos, assim, passou a fazer parte do grupo de bebidas que possuem propriedades funcionais (FIRMINO, 20II).

A sua composição química pode variar, assim como a das folhas utilizadas para sua produção como bebida, que passa por diferentes momentos de preparo realizados através da infusão das folhas da Camellia sinensis, pois elas podem originar até cinco tipos de chás diferentes, o chá verde, preto, vermelho, branco e amarelo também conhecido como Oolong (BELTRAN et al., 2014).

Considerando a assimetria no processamento das folhas, cada chá apresenta diferenças de sabor, aspecto e propriedades antioxidantes, especificamente, no caso dessas últimas propriedades, ocorrem mudanças significativas de um chá para outro (PAGANINI COSTA, DA SILVA, 20II).

Durante a produção do chá verde após a lavagem das folhas, elas são picadas e passam por um cozimento a vapor se tornando flexíveis e maleáveis para serem trabalhadas. As mesmas são enroladas e colocadas em bandejas aquecidas para ocorrer o rompimento da estrutura celular se obtendo o sabor desejado do chá. Logo após, elas são secas até que se tenha apenas $2 \%$ de sua umidade original (PAGANINI COSTA, DA SILVA, 20II)

É necessário que as folhas recém-colhidas passem pelo aquecimento no cozimento a vapor para ocorrer a inativação das enzimas catalíticas, é o que se chama de estabilização das folhas. Este processamento deve ser realizado imediatamente após a colheita, desta forma, previne-se a oxidação dos bioativos do chá, obtendo um produto seco, estável, e de melhor qualidade (MATSUBARA, RODRIGUEZ-AMAYA, 2006).

\subsection{Camellia sinensis (chá verde) e suas propriedades}

Os principais constituintes do chá incluem proteínas, polissacarídeos, polifenóis, minerais e carboidratos, incluindo celulose, fibras, quase insolúveis em água. Além disso contém amidas, ácidos proteicos nucleicos, e aminoácidos, como a teanina e o ácido glutâmico, bem como arginina e ácido aspártico. As folhas de chá apresentam vitamina $\mathrm{A}$, tiamina $\left(\mathrm{B}_{1}\right)$, riboflavina $\left(\mathrm{B}_{2}\right)$, niacina $\left(\mathrm{B}_{3}\right)$, vitamina $\mathrm{K}$ e ácido ascórbico, embora o processo de fermentação resulte em uma redução da quantidade de alguns componentes. Contém também elementos minerais como zinco, ferro, cobre, manganês, sódio, potássio, 
bem como níquel, fósforo e cálcio. Outro grupo de constituintes importante do chá é o alcaloide, que inclui cafeína, teofilina e teobromina (GRAMZA-MICHALOWSKA, BAJERSKA-JARZEBOWSKA, 2007).

Dentre os quatro tipos de chá, o chá verde, ou o chá não fermentado, contém a maior quantidade de flavonoides, sendo que as catequinas compreendem $80 \%$ a $90 \%$ dos flavonóides totais, com galato de epigalocatequina (EGCG), sendo a catequina mais abundante (48-55\%) e o componente ativo mais significativo, seguida das outras catequinas, epigalocatequina (EGC), com cerca de 9-12\%, Galato de epicatequina (ECG) com 9-12\% e epicatequina (CE) com cerca de 5-7\% (PASTORE; FRATELLONE, 2006).

Além das catequinas, a composição química do chá verde também inclui $15 \%$ de proteínas, $4 \%$ de aminoácidos, $26 \%$ de fibras, $7 \%$ de outros carboidratos, $7 \%$ de lipídios, $2 \%$ de pigmentos e 5\% de minerais A concentração usual de polifenóis totais em folhas de chá verde seco é de cerca de 8\% a 12\% (PASTORE; FRATELLONE, 2006).

As catequinas presentes no chá, são compostos incolores e solúveis em água que conferem amargura e adstringência à infusão de chá verde. A maioria das características do chá fabricado, como o aroma, cor e sabor, estão associados, direta ou indiretamente, a modificações nas catequinas (WANG, PROVAN, HELLIWELL, 200o).

As catequinas são potentes eliminadoras de radicais livres, devido ao seu potencial de redução de elétrons. A taxa de reação com os radicais livres e a estabilidade dos radicais antioxidantes resultantes contribuem para a reatividade do antioxidante (ANANINGSIH, SHARMA, SHOU, 2013).

O chá verde é uma fonte potente de antioxidantes benéficos, pois é rico em polifenóis, incluindo catequinas, teaflavinas e as arubiginas. A folha possui a presença de um conhecido antioxidante, entre os quais EGCG (epigalocatequina-galato), bem como flúor e taninos (SHARANGI, 2009). Os flavonoides encontrados no chá verde e preto são potentes agentes de eliminação de radicais e podem ser ativos como antioxidantes no trato digestivo ou em outros tecidos após a absorção (RIETVELD, WISEMAN, 2003).

As propriedades anti-inflamatórias da Camellia Sinensis também estão bem estabelecidas na literatura. Diferentes flavonoides da Camellia Sinensis apresentam ação anti-inflamatória, inibindo as enzimas ciclooxigenase $2(\mathrm{COX}-2)$ e lipoxigenase do metabolismo do ácido araquidônico e a formação de thromboxane e I2-ácidohidroxiheptadecatrienoico (ADCOCKS, 2002). 
A inflamação crônica está envolvida numa gama de diferentes tipos de câncer, doenças cardiovasculares, obesidade, diabetes e hipertensão e os inibidores da COX-2 vem sendo estudados como potenciais agentes quimioprotetores em câncer colorretal (ADCOCKS, COLLIN, BUTTLE, 2002; CHUNG et al., 2015).

Outra propriedade funcional muito importante da Camellia Sinensis é a capacidade antimicrobiana contra várias bactérias. $O$ mecanismo proposto para essas atividades antimicrobianas é que as catequinas bactericidas atuam prejudicando as membranas bacterianas. Os receptores ou sensores sensíveis ao nutriente são detectados por nutrientes orais ou intravenosos incluindo nutracêuticos imunomoduladores, que, através de fibras vagais aferentes, se projetam no núcleo dorso motor e interagem com o hipotálamo (SATO, MIYATA, 200o). Aumenta a atividade eferente do tímico vagal e linfonodo vagal, estimulando a liberação de células $\mathrm{T}$. Simultaneamente, ocorre diminuição dos eferentes esplênicos, inibindo a absorção de linfócitos. $O$ efeito líquido é um aumento na imunidade celular e humoral circulante (SATO, MIYATA, 2000). Adicionalmente, os estudos têm sugerido propriedades antimutagênicas, anti-apopitóticas e anti-angiogênicas da C.sinensis (CHUNG et al., 2015).

Assim, a planta Camellia Sinensis, nas suas diferentes formas (chá, extrato) tem ganhado bastante atenção pelos diversos benefícios que impactam na saúde. Por conta disso, incluiu-se os extratos de chá em suplementos dietéticos e alimentos funcionais (BHARDWAJ, KHANNA, 2013; GOTTLIEB et al., 2017).

\subsection{Composição química e biodisponiblidade do chá verde}

O chá verde como já visto é uma das bebidas mais consumidas no mundo, e sabe-se também que é um importante alimento funcional. O uso de plantas na cura e prevenção de doenças vem sendo praticado há muito tempo devido à presença de substâncias ativas, que contribuiu para a terapêutica moderna

Segundo a Agência Nacional de Vigilância Sanitária (ANVISA) o alimento funcional é "aquele alimento ou ingrediente que, além das funções nutritivas básicas, quando consumido como parte da dieta usual, produz efeitos metabólicos e/ou fisiológicos e/ou efeitos benéficos à saúde, devendo ser seguro para consumo sem supervisão médica" 
O chá verde, não fermentado, é produzido a partir das folhas frescas da planta Camellia sinensis, que contém: água, proteínas, hidratos de carbono, minerais, vitaminas e polifenóis do tipo flavonoides. (FREITAS, 2007).

A composição química do chá verde está demonstrada no quadro I.

Quadro I - Composição do chá verde (por ıoo g)

\begin{tabular}{|c|c|c|}
\hline Chá verde & Folha & Infusão* \\
\hline \multicolumn{3}{|l|}{ Macronutrientes (g) } \\
\hline Proteínas & 24 & $0, \mathrm{I}$ \\
\hline Lipídios & 4.6 & o \\
\hline Açúcares & 35,2 & o,I \\
\hline Fibra & го,6 & o \\
\hline Cinzas $(\mathrm{g})$ & 5,4 & $0, \mathrm{I}$ \\
\hline Minerais (mg) & - & - \\
\hline Cálcio & 440 & 2 \\
\hline Fósforo & 280 & I \\
\hline Ferro & 20 & O,I \\
\hline Sódio & 3 & 2 \\
\hline Potássio & 2200 & I8 \\
\hline Vitaminas & - & - \\
\hline Vitamina A (UI) & 13000 & o \\
\hline Tiamina $(\mathrm{mg})$ & 0,35 & o \\
\hline Riboflavina (mg) & $\mathrm{I}, 4$ & 0,03 \\
\hline Niacina (mg) & 4 & o,I \\
\hline Vitamina C (mg) & 250 & 4 \\
\hline Cafeína (mg) & 2,3 & 0,02 \\
\hline
\end{tabular}

Tabela adaptada de Figueroa, Rodríguez e Muniz (2004)

*Infusão preparada com 3 gramas de folha em roo $\mathrm{ml}$ de água fervente por 2 minutos.

A concentração de catequinas na bebida varia de acordo com a preparação do chá, mas de forma geral o chá verde é preparado em uma proporção de I $g$ de folhas para Ioo $\mathrm{ml}$ de água quente (deve-se desligar o fogo antes que se inicie a fervura da água) por 3 minutos, contém cerca de $35-45 \mathrm{mg} /$ ıoo $\mathrm{ml}$ de catequinas e $6 \mathrm{mg} /$ ıoo $\mathrm{ml}$ de cafeína. Um 
estudo realizado demonstrou que depois de I hora da ingestão de 6-12 copos (200 $\mathrm{ml}$ cada) de chá verde, os níveis plasmáticos de catequinas são baixíssimos, geralmente I $\mu \mathrm{M}$, sugerindo que o consumo deve ser feito de forma fracionada e várias vezes ao dia para que essas

concentrações não sejam insignificantes e possam trazer benefícios a saúde. (LAMARÃO et al, 2009)

\subsection{Farmácia magistral}

Define-se a farmácia como um estabelecimento de manipulação de fórmulas prescritas e oficinais, de mercado de fármacos, drogas, insumos de socorro e correlatos. Uma distinção excepcional de drogaria para farmácia é o fato de que na drogaria não pode suceder a manipulação de remédios, permitindo somente a venda de drogas, remédios, insumos farmacopolas e correspondentes em seus recipientes originais, ou seja, industrializados (CONSELHO REGIONAL DE FARMÁCIA, 2018)

Pode-se considerar fórmulas manipuladas aquelas que são desenvolvidas dentro da farmácia de maneira que siga a prescrição de um profissional da saúde habilitado para tal função, de forma que atenda o paciente individualmente e seguindo a sua composição, posologia, forma farmacêutica e modo de usar. Entretanto, as formas oficiais são as descritas no Formulário Nacional da Anvisa ou em outros formulários oficialmente reconhecidos (MOTA, 2017; FORMULÁRIO NACIONAL DA ANVISA, 2020)

Para diferenciação do exercício da farmácia magistral é conciso situar as contestações entre o procedimento artesanal de manipulação de antálgicos e o método industrial. A manipulação magistral pode ser acentuada como a elaboração, combinação, modificação, recipiente e a rotulação de um fármaco ou produto a partir de uma ordem. Já o processo industrial é qualificado pela fabricação, elaboração, convertimento ou processamento de um remédio ou produto em ampla linha graduada, diferenciando lotes, com forma boticária e dose unificada, definida.

Assim sendo, a diferença principal em meio aos medicamentos produzidos numa farmácia de manipulação em afinidade as drogas industrializadas é a adaptação da formulação (dose, quantidade ou forma farmacêutica) a cada paciente. Também é aceito ao 
prescritor situar cooptações dentre os fármacos diferentes numa mesma formulação (FARIAS, 2020).

São estimados possíveis acrescimentos do medicamento manuseado, a facilidade posológica, a probabilidade de opção da forma farmacêutica, consentindo ao prescritor a alternativa da fórmula que mais se acomode à via de comando selecionada ou às categorias do paciente, a probabilidade de desempenho de medicamentos por meio da manipulação de medicamentos que foram cessados pelos ambulatórios, à moderação, à personalização da clínica e à união multiprofissional, qualificada pela trilogia da saúde, o relacionamento entre farmacêutico, médico e paciente (DIAS, 2020).

5.5 Atuais exigências da vigilância sanitária para o controle de qualidade nas farmácias magistrais

$\mathrm{Na}$ indústria de fármacos, a aspereza e as cobranças se ativaram com o boletim de legislações inovadoras, diferenciando o comércio industrial de remédios como um dos mais regulamentados. A principal normativa que abona a propriedade dos antálgicos no Brasil através da regulamentação das boas práticas de fabricação é a RDC nº 30I/2019 (BRASIL. MINISTÉRIO DA SAÚDE, 2019)

Este alvará aboliu a RDC no $17 / 2010$ que foi culpada por amplo impacto para o campo, constituindo as novas diretrizes para a concretização das verificações sanitárias efetivadas pelos órgãos regulatórios, cada vez mais indiscutíveis. Para que as indústrias farmacêuticas competissem tal alvará, foi cogente uma atualização nas alas de produção, sendo o apontamento de medicamentos exclusivamente consagrados posteriormente a aprovação de qualidades aceitáveis durante a revista regulatória.

A RDC 301/2019 se tornou cada vez mais compreensiva que a velha RDC 17/2010. Além de conservar os temas de abonação da propriedade, reivindicações, recolhimento de produto, limpeza individual, auto inspeção e auditoria da qualidade, acomodações e aparelhamentos, propriedade da água empregue na indústria farmacêutica, processos de limpeza e diminuição das infecções cruzadas e microbianas durante a produção, junto a ela foram estabelecidas 14 Instruções Normativas (IN) de argumentos característico.

Se a RDC 17/2010 já apropinquar-se de argumentos mais exclusivos, e proporcionava uma cobrança máxima para a produção de uma droga industrializada, 
quando conferida à RDC 67/2007 para elaborações manipuladas, a RDC 301/2019 acarreta uma rigidez com muito detalhamento das Fluxogramas Normativos.

\subsection{A vigilância sanitária nas farmácias magistrais}

A Anvisa é o órgão regulador responsável pelo controle sanitário no Brasil, sendo uma autarquia Federal ligada ao Ministério da Saúde com a finalidade de "promover a proteção da saúde da população por intermédio do controle sanitário da produção e da comercialização de produtos e serviços submetidos à vigilância sanitária, inclusive dos ambientes, dos processos, dos insumos e das tecnologias a eles relacionados (DE ALMEIDA, 2012).

O termo controle é usado para os atos sanitários sobre ditos-cujos, celeridades, substâncias, produtos, empregos e assessorias, para que estes não se afastem de leis préestabelecidas. A autoridade inclui alvará, ordem de funcionamento e apontamento, meios usados pela Administração Pública para interferir nas prestezas privadas e as acomodar aos negócios grupais (DE ALMDEIDA, 2012).

Para que a vigilância sanitária consiga desempenhar seus diferentes aprendizados é aproveitada a instrumentação legal, isto é, as normas e cláusulas técnicas constituem os algoritmos que têm como objetivo garantir os começos do bem-estar evidente, seguindo o desenvolvimento da ciência e da tecnologia. A Anvisa convidou para um treino, fiscais farmacêuticos de todo o Brasil, que agiam nas revistas de drogarias e, sobretudo, para arriscar colocar a unificação de seus atos aduaneiros.

Em seguida o andamento do treino a RDC 214/2006 teve algumas atualizações e foi divulgada a RDC 67/2007, que é a lei empregada desde então nas revistas em drogarias magistrais (FORMULÁRIO NACIONAL DA ANVISA, 2020). Os principais desafios encontrados na fiscalização destes estabelecimentos são a falta de tempo para execução de todas as avaliações e orientações necessárias, os níveis de conhecimento diferenciados entre os inspetores resultando em divergentes entendimentos legais e entraves políticos

\subsection{Qualidade dos medicamentos}

Existem diversos fatores que influenciam na qualidade dos medicamentos manipulados, nos quais contribuem para a distribuição, produção, uso dos produtos, transporte e desenvolvimento. Por conseguinte, ao debatermos sobre o controle de 
qualidade dos remédios de manipulação, precisa-se considerar alguns parâmetros, como: a solução dos princípios ativos dentro do permitido, igualdade nos conteúdos de cada dose manipulada, não permitindo a contaminação, seja ela cruzada ou microbiológica, aspectos até o momento do uso, eficácia terapêutica e manutenção da potência (BARATA-SILVA, 2017).

Há muitos anos, o controle de qualidade dos fármacos aferia apenas a qualidade dos produtos das matérias-primas utilizadas no processo de produção e nos produtos finais. Nos dias atuais, diversas funções podem ser conferidas ao controle de qualidade como, por exemplo, preparação, revisões das metodologias pré-estabelecidas aos processos, incubação de particularizações dos ingredientes, materiais do recipiente e produtos finais, cumprimento de apreciações, sustentação e guarda dos apontamentos analíticos, laboração de planos de amostragem, instruções de estudos de equilíbrio, envio de pareceres e sobretudo, a verificação de todas as etapas durante a produção (BARATA-SILVA, 2017).

Na farmácia de manipulação, a produção acontece diante de uma determinação clínica e para um paciente individualizado, não há concepção de lotes e a ampla disparidade de formulações impede a efetivação dos exames de controle de qualidade no produto acabado. Ademais, como são lançadas poucas quantidades por vez, a fabricação extra para a verificação da qualidade com metodologias mais cuidadosas, como os químicos ou biológicos, ou a manutenção de amostras de contraprova, é considerada financeira e tecnicamente difícil (ARAÚJO, 2017).

Assim, é essencial que nesse mercados grande parte das etapas aplicadas no método sejam monitoradas e controladas, de maneira que garanta a qualidade do produto final. Idealmente, a fabricação de um remédio seguro solicita a comprovação, mediante a experimentos de controle de qualidade, da harmonia com propriedades de conteúdo do princípio ativo por unidade; posológica, igualdade, equilíbrio e predicados apropriados, contendo a rotulação (DIAS, 2020; BISOGNIN, 2013).

Existem outros grandes feitios que regulamentam a qualidade do produto acabado. São eles: volume médio, peso, igualdade das porções, onde são analisadas a disseminação ou transformação dos conteúdos por unidade, a solução, equivalem a configuração de liberação do fármaco para ser meditado pelo organismo. Também são acuradas as propriedades físicas e microbiológicas que precisam acatar alcances verificados pelas farmacopeias e bibliografias auxiliares (BISOGNIN, 2013). 
O recipiente empregado para armazenar o produto necessita de passar por uma escalação de maneira a garantir amparo versus os fatores ambientais atribulados (umidade, contaminação microbiana, oxigênio, luz solar e outros), imponderações físicas (choque, impacto, perfuração e vibração) durante o armazenamento e transporte, visando principalmente conservar os modelos de qualidade durante o andamento do uso (SILVA, 2017).

Além disso, falando em proteção a rotulação com articulares adequados consente o usufrutuário a inconfundível identificação, rastreabilidade e mantimento do medicamento incluso aos modelos alcançados, além de elementos de direção como ao emprego de produto.

O monitoramento da metodologia produtiva manipuladamente poderia ser concretizado mediante o comando da propriedade de ingredientes e recipientes, de modelos de produtos acabados de diferentes configurações farmacêuticas, do controle do ambiente de manipulação, entre outros parâmetros que funcionam como indicadores desse processo.

Para implantação do controle de qualidade, a farmácia magistral, além de atender as exigências legais, deve seguir as seguintes etapas: verificação das especificações de qualidade, levantamento dos métodos analíticos validados, elaboração de procedimentos operacionais padronizados (POP's), levantamento de equipamentos, utensílios e reagentes necessários e planejamento do espaço físico (BISOGNIN, 2013; SILVA, 2017).

\subsection{Mecanismos de degradação}

Quando ocorre algum tipo de instabilidade nos medicamentos, em certos casos, esta pode ser detectada através de alguma mudança na aparência física, como: cor, sabor, odor ou textura da fórmula. Por outro lado, as alterações químicas que possam surgir não são tão evidentes e por muitas vezes só se consegue determinar por meio de análises químicas dos compostos.

Muitos fármacos são suscetíveis a algum tipo de decomposição química, quando formulados no estado liquido ou mesmo em formas farmacêuticas solidas. Tal degradação não só leva a uma perda de potência do fármaco, mas pode, em alguns casos, causar alterações na aparência física das fórmulas farmacêuticas, como por exemplo, a descoloração após a decomposição fotoquímica do medicamento. 
A instabilidade química está sempre associada a uma perda de potência e de qualidade do medicamento. A identificação, o doseamento dos produtos e degradação permitindo um melhor conhecimento da cinética de degradação, assim como, conhecer as condições para melhorar os medicamentos magistrais que apresentam estruturas químicas através de diversos mecanismos tais como: hidrólise, oxidação, racemização, isomerização, desidratação e fotodegradação (MARQUES, 2014).

\section{EXEMPLOS DE MÉTODOS DE ANÁLISE DE QUALIDADE DO CHÁ VERDE}

Foram analisadas 7 amostras de Camellia Sinensis (chá verde) numa cidade de São Paulo, sendo elas de diferentes fabricantes, foi pesado em uma balança $50 \mathrm{~g}$ de cada amostra, logo após foram colocadas em uma superfície plana, o material entranho coletado foi pesado logo assim que separado. Com base no peso inicial da amostra foi realizado o cálculo de porcentagem do material estranho. (Michelin, D., 2013)

Podemos analisar o resultado na tabela abaixo:

Tabela 1. Determinação de material estranho nas amostras de Camellia sinensis (chá verde).

\begin{tabular}{lll}
\hline Amostras & Materiais estranhos encontrados & Porcentagem \\
\hline 1 & Caules & 6,46 \\
2 & Caules e um inseto & 7,72 \\
3 & Caules & 56 \\
4 & Caules & 1,61 \\
5 & Caules e um inseto & 43,27 \\
6 & Caules & 3,7 \\
7 & Caules e um inseto & 52,63 \\
\hline
\end{tabular}

Figura

disponivel

em:

<:/Users/Administrador/Downloads/camelia\%20sinesi\%202.pdf $>$ acesso em 22 de ago 202I.

A Farmacopeia brasileira (2019) determina que a porcentagem de matérias estranho não deve ser superior a $2 \%$, como está presente na tabela uma das amostras estão dentro da margem, as outras apresentaram porcentagem superior a 2\%. (FB 60, 2019, p.316).

Em mercados localizados em Belo Horizonte foram obtidas outras is amostras de chá verde, para ser analisadas, para determinar o teor de umidade a analise foi feita da seguinte maneira, foi colocado $3 \mathrm{~g}$ das amostras já pesadas em cadinho de porcelana a ${ }_{12} 0^{\circ} \mathrm{C}, \operatorname{logo}$ após que a temperatura ambiente resfriou o processo foi se repetindo até que o peso da amostra se tornou constante. Posteriormente, em uma mufla foram colocadas as 
amostras em $500{ }^{\circ} \mathrm{C}$ durante 3 horas. Com a queda da temperatura, para obtenção de teor de cinzas as amostras foram pesadas. (Menezes, J., 2014)

Como descrito na Portaria no 519 de 26 de junho de 1998 (ANVISA) é estabelecido que para o teor de umidade do chá verde o valor máximo é de 12\%. Ao analisar a tabela 2 podemos observar que o valor exigido pela ANVISA só está de acordo em 12 amostras, conseguindo provar boas condições, o excesso de umidade pode favorecer a proliferação de micro-organismo. Para o teor de cinzas é permitido pela legislação o valor $8 \%$, no entanto, a quantidade de resíduos não volátil presente na amostra estavam dentro do valor permitido. (Brasil,1998)

\begin{tabular}{cccc} 
Tabela 2 - Resulta dos para o teor de umidade e cinzas das amostras de chá comercializa das em \\
\multicolumn{4}{c}{ Belo Horizonte-MG. } \\
\hline Amostra & Peso inicial (g) & Umidade (\%) & Cinzas (\%) \\
\hline 1 & 3,0 & $11,4 \pm 0,5$ & $6,2 \pm 0,1$ \\
2 & 3,0 & $11,3 \pm 1,1$ & $5,6 \pm 0,3$ \\
3 & 3,0 & $11,8 \pm 2,1$ & $5,7 \pm 0,4$ \\
4 & 3,0 & $11,2 \pm 0,1$ & $5,7 \pm 0,5$ \\
5 & 3,0 & $9,3 \pm 0,1$ & $5,6 \pm 0,3$ \\
6 & 2,9 & $9,2 \pm 0,1$ & $4,9 \pm 0,3$ \\
7 & 3,0 & $7,1 \pm 0,3$ & $4,7 \pm 0,1$ \\
8 & 3,0 & $9,3 \pm 0,2$ & $6,0 \pm 0,4$ \\
9 & 2,9 & $9,5 \pm 0,2$ & $4,2 \pm 0,1$ \\
10 & 3,0 & $10,9 \pm 1,6$ & $5,7 \pm 0,3$ \\
11 & 3,0 & $11,1 \pm 1,9$ & $4,5 \pm 0,2$ \\
12 & 2,9 & $5,7 \pm 0,1$ & $5,4 \pm 0,2$ \\
13 & 3,0 & $7,1 \pm 0,6$ & $4,8 \pm 0,3$ \\
14 & 3,0 & $5,7 \pm 0,2$ & $4,7 \pm 0,1$ \\
15 & 3,0 & $2,9 \pm 0,1$ & $4,1 \pm 0,1$ \\
\hline
\end{tabular}

Figura disponivel em < http://www.abq.org.br/cbq/2014/trabalhos/13/5839-15059.html> acesso em 22 de ago 202I.

\section{CONCLUSÃO}

O mercado de plantas medicinais e fitoterápicos mostra-se em crescente ascensão, principalmente nos países desenvolvidos, com uma indústria que movimenta milhares de dólares por ano. Trata-se de um negócio que envolve toda uma cadeia produtiva, desde o cultivo até o produto final e que não se restringe apenas a fins medicamentosos. 
O chá verde possui diversas atividades biológicas benéficas para saúde do homem, sendo interessante fazer o estudo dessa planta associado com outras plantas ou componentes químicos isolados para potencializar a ação do mesmo. Ainda é muito carente o estudo sobre associações com outros compostos ou insumos que sejam testados cientificamente, pois atualmente é muito escasso esse tipo de estudo. Por isso é relevante a realização de mais estudos para melhor aproveitamento dessa planta tão multifuncional.

A preparação de medicamentos magistrais é uma prática ancestral na atividade farmacêutica e constitui uma realidade atual nas atividades terapêuticas. O conhecimento do processo de fabricação e controle de qualidade das formas galênicas é fundamental para assegurar a qualidade do produto.

Faz-se necessário conhecer a estabilidade e condições de armazenamento de modo a estabelecer um prazo de utilização que permita a manutenção das características iniciais do produto. Atualmente estamos numa era de grande ênfase no que diz respeito à qualidade e documentação de medicamentos manipulados. Portanto, cabe ao farmacêutico que se dedique à preparação magistral, estar familiarizado e respeitar os regulamentos de qualidade sobre medicamentos manipulados

\section{REFERÊNCIAS BIBLIOGRÁFICAS}

ANVISA. AGENCIA NACIONAL DE VIGILÂNCIA SANITÁRIA. Farmacopeia Brasileira, volume I. 6a Ed. Brasilia,2019b

ADCOCKS, C.; Collin, P.; Buttle, D. Catechins from green tea (Camellia sinensis) inhibit bovine and human cartilage proteoglycan and type II collagen degradation in vitro. The Journal of nutrition. v. 132, n. I, p. 34I-6, 2002. doi: 10.1093/jn/132.3.34I

AMARAL, F. (2003). Avaliação da qualidade de drogas vegetais comercializadas em São Luís/Maranhão. Revista Brasileira de Farmacognosia.

ANANINGSIH, V. K.; Sharma, A.; Zhou, W. Green tea catechins during food processing and storage: A review on stability and detection. Food Research International, v. 5o, n. 2, p. 469-79, 2013. doi: 10.1016/j.foodres.2011.03.004

ARAÚJO, Kaline Vanessa Martins. Acompanhamento da produção de medicamento e demais produtos manipulados em uma farmácia magistral do município de Mossoró RN. 2017 . 
BARATA-SILVA, Cristiane et al. Desafios ao controle da qualidade de medicamentos no Brasil. Cadernos Saúde Coletiva, v. 25, p. 362-370, 2017.

BELTRAN, C. C.; SILVA, N. A. S.; GRIGNOLI, L. C. E.; SIMIONATO, M. I. V.; GRIGNOLI, C. R. E. Os benefícios do chá verde no metabolismo da gordura corporal. Revista científica da FHO, v.2, p. 41- 49, 2014.

BIANCO, A. C. Hormônios tireóideos, UCPs e termogênese. Arquivos Brasileiros Endocrinologia e Metabolismo, São Paulo, v. 44, n. 4, ago. 2000.

BISOGNIN, NAGALI SEGATTO et al. CONTROLE DE QUALIDADE APLICADO AO MEDICAMENTO MAGISTRAL. Anais do Salão de Ensino e de Extensão, p. I4I, 2013

BRASIL, Ministério da Saúde. Secretaria de Ciência, Tecnologia e Insumos Estratégicos. Departamento de Assistência Farmacêutica. Política e Programa Nacional de Plantas Medicinais e Fitoterápicos/Ministério da Saúde, Secretaria de Ciência, Tecnologia e Insumos Estratégicos, Departamento de Assistência Farmacêutica - Brasília: Ministério da Saúde, 2016.19o $\mathrm{p}$

BRASIL. MINISTÉRIO DA SAÚDE, 2019. [Disponível em: http://antigo.anvisa.gov.br/documents/I018I/5389382/\%286\%29RDC_301_2019_COMP .pdf/7d99ico4-e7ar-4957-aed5-3689c62913b2] Acesso em: io de out. 2021

BRASIL. Política Nacional de Práticas Integrativas e Complementares no SUS - PNPICSUS. Secretaria de Atenção à Saúde. Departamento de Atenção Básica. Brasília: Ministério da Saúde, 2006.

BRASIL. RDC no 67, de 8 de outubro de 2007, republicada em 21 de agosto de 2006. Agência Nacional de Vigilância Sanitária Dispõe sobre as Boas Praticas de Manipulação de Preparações Magistrais e Oficinais para Uso Humano em farmácias. Disponível em: http://www.farmacia.ufg.br/uploads/130/original. Acesso em: Io out. 2021.

BRASIL. PORTARIA n ${ }^{\circ} .519$ de 26 de Junho de 1998 (ANVISA). Regulemento Técnico para fixação de Identidade e Qualidade de "Chás-Plantas destinadas à preparação de infusões ou decocções”. Diário Oficial da República Federativa do Brasil, Poder Executivo, Brasília, DF, 29 de jun.I998.

CHUNG, K. T.; WONG, T. Y.; WEI, C. I.; HUANG, Y. W.; LIN, Y. Tannins and human health: a review. Critical Reviews in Food Nutrition, Amherst, v. 38, n. 6, p. 421464, 1998.

DE ALMEIDA, Maria Letice Couto; DO NASCIMENTO FILHO, Armando Pereira. Análise e discussão de aspectos críticos da resolução 67/2007 da ANVISA para as farmácias com manipulação. Infarma-Ciências Farmacêuticas, v. 22, n. II/12, p. 13-24, 2012.

DIAS, Kays Lorena Feitosa; FREY, Jaqueline Almeida; DE OLIVEIRA MARQUEZ, Carolinne. AS VANTAGENS DOS MEDICAMENTOS MANIPULADOS $\mathrm{X}$ 
MEDICAMENTOS INDUSTRIALIZADOS: doi. org/I0.29327/217514.6. 12-29. Revista Ibero-Americana de Humanidades, Ciências e Educação, v. 6, n. I2, p. Io-Io, 2020

DUARTE, M. R.; MENARIM, D. O. Morfodiagnose da anatomia foliar e caulinar de Camellia sinensis (L.) Kuntze, Theaceae. Revista Brasileira de Farmacognosia, v. 16, n. 4, p. 545-551, 2006.

FARIAS, Fernanda Fernandes et al. Divergências nas exigências regulatórias para preparações magistrais e medicamentos industrializados. Infarma-Ciências Farmacêuticas, v. 32, n. 2, p. 128-136, 2020.

FIGUEROA TTH, RODRIGUEZ-RODRIGUEZ E, MUNIZ FJS. El té verde uma buena elección para La prevención de enfermedades cardivasculares. Arch Latinoam Nutr 2004;54(4):380-394.

FIRMINO, Luziana de Azevedo. Avaliação da qualidade de diferentes marcas de chá verde (Camellia sinensis) comercializadas em Salvador-Bahia. 2013. Disponível em: https://www.repositorio.ufba.br/ri/handle/ri/8804. Acesso em: ro out 202I.

FORMULÁRIO NACIONAL DA ANVISA [Disponível em: https://www.gov.br/anvisa/pt-br/assuntos/farmacopeia/formulario-nacional] Acesso em 06 de out.. 202I

FREITAS HCP, Navarro F. O chá verde induz o emagrecimento e auxilia no tratamento da obesidade e suas comorbidades. Revista Brasileira de Obesidade, Nutrição e Emagrecimento 2007

GIL, A. Como elaborar projetos de pesquisa. Atlas, São Paulo, 2007.

GRAMZA-Michalowska, A.; BAJERSKA-Jarzebowska, J. Folhas de Camellia sinensis: Planta Cervejeira Ordinária ou Fonte Super Antioxidante?. Comida, v. I, n. I, p. 56-64, 2007 .

LAMARÃO RC, FIALHO E. Aspectos funcionais das catequinas do chá verde no metabolismo celular e sua relação com a redução da gordura corporal. Rev Nutr 2009;22(2):257-69.

MARQUES, Rodrigo Lopes. Estabilidade dos medicamentos manipulados. 2014

MATSUBARA, S.; RODRIGUEZ-AMAYA, D. B. Conteúdo de miricetina, quercetina e kaempferol em chás comercializados no Brasil. Ciência Tecnologia Alimentação, Campinas, v. 26, n. 2, p. 380-385, abr./jun. 2006a.

MATSUBARA, Simara; RODRIGUEZ-AMAYA, Delia B. Conteúdo de miricetina, quercetina e kaempferol em chás comercializados no Brasil. Ciência e Tecnologia de Alimentos, v. 26, n. 2, p. 380, 2006. Disponível em: http://www.scielo.br/pdf/\%oD/cta/v26n2/30186.pdf. Acesso em: 13 out. 2021 
Michelin, D. C. (2013). Avaliação da qualidade de amostras de Camellia sinensis (L.) Kuntze (Theaceae) comercializadas nomunicípio de Araras - SP. Revista de Ciências Farmacêuticas Básica e Aplicada.

Menezes, J. (.-M. (2014). análise da qualidade de amostras de camellia sinensis (chá verde) comercializadas em mercados de belo horizonte. Congreso brasileiro de quimica.

MOTA, Vivian Aline Mariano; JUNIOR, João Augusto Oshiro; CHIARIANDRÉO, Bruna Galdorfini. O controle da contaminação microbiológica de produtos magistrais. Revista Brasileira Multidisciplinar, v. 20, n. I, p. 33-48, 2017.

PAGANINI-COSTA, P.; CARVALHODA-SILVA, D. Uma Xícara (chá) de Química. Revista Virtual Química, v.3, n.I, p.27-36, 201 .

PASTORE, R.L.; FRATELlONE, P. Potenciais Benefícios para a Saúde do Chá Verde (Camellia sinensis): Uma Revisão Narrativa. Explore, v. 2, n. 6, p. 531-39, 2006. doi: I0.1016/j.explore.2006.08.008

SENGER, A.E.V.; SCHWANKE, C.H.A.; GOMEs, I; GOTTLIEB, M.G.V. Effect of green tea (Camellia sinensis) consumption on the components of metabolic syndrome in elderly. J Nutr Health Aging., v I6, n. 9, p. 738-42, 2012. doi: 10.1007/si2603-012-008I-5.

SILVA, Leandro de Oliveira; SILVA, Rosemeire Lima da. Controle de qualidade quanto à determinação de peso nas cápsulas manipuladas em farmácias da cidade de Mogi Guaçu, SP. Revista Foco: caderno de estudos e pesquisas, n. 7, 2016. Disponível em: http://www.revistafoco.inf.br/index.php/ . Acesso em: Io out. 202I 